\title{
Association of $X R C C 5$ polymorphisms with COPD and COPD-related phenotypes in the Han Chinese population: a case-control cohort study
}

B. Wang ${ }^{1 *}$, J. Yang ${ }^{1 *}$, J. Xiao ${ }^{1}$, B. Liang ${ }^{1}$, H.X. Zhou ${ }^{1}$, Z. Su ${ }^{1}$, S. Xu ${ }^{1}$,

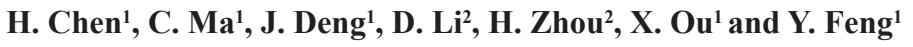

${ }^{1}$ Department of Respiratory Medicine, West China Hospital, Sichuan University, Chengdu, Sichuan, China

${ }^{2}$ The Second People's Hospital of Hongya County, Meishan, Sichuan, China

*These authors contributed equally to this study.

Corresponding authors: X. Ou / Y. Feng

E-mail: ouxuemei1115@163.com / fengyulin_1115@163.com

Genet. Mol. Res. 13 (3): 7070-7078 (2014)

Received May 24, 2013

Accepted November 13, 2013

Published January 24, 2014

DOI http://dx.doi.org/10.4238/2014.January.24.11

\begin{abstract}
Genome-wide association studies (GWAS) and integrative genomic approaches have demonstrated significant associations between chronic obstructive pulmonary disease (COPD) and polymorphisms of the $\mathrm{X}$-ray repair cross-complementing protein 5 gene (XRCC5) in non-Asian populations. We investigated whether XRCC5 polymorphisms might be associated with COPD susceptibility and COPD-related phenotypes in the Chinese Han population. Nine single nucleotide polymorphisms (SNPs) (rs3821104, rs12470053, rs207936, rs3770498, rs6704622, rs3770492, rs4674066, rs7573191, and rs207906) in the XRCC5 gene were genotyped in a case-control study including 680 COPD patients and 687 controls. To estimate the strength of association, odds ratios (ORs) were calculated and the effects of potentially confounding variables were tested by logistic regression analysis. The association between haplotypes
\end{abstract}


and COPD outcome was also assessed. Our data identified that the SNP rs207936 was associated with COPD with an adjusted P value of 0.038 , which was also found when analyzing only data of current smokers $(\mathrm{P}=$ 0.046). No significant associations were found between any of the SNPs and pulmonary function. Eight SNPs (rs3821104, rs12470053, rs207936, rs3770498, rs6704622, rs3770492, rs4674066, and rs7573191) showed strong linkage disequilibrium $\left(\mathrm{R}^{2} \geq 0.9\right)$. Two major haplotypes were observed and showed a significant difference between case and control groups ( $\mathrm{P}=0.0054$ and 0.0081 , respectively). The present study showed that the XRCC5 locus might be a contributor to COPD susceptibility in the Chinese Han population.

Key words: Association analysis; Chronic obstructive pulmonary disease; COPD-related phenotypes; Case-control study; XRCC5

\section{INTRODUCTION}

Chronic obstructive pulmonary disease (COPD) is one of the leading causes of morbidity and mortality worldwide, and is predicted to become the 4th leading cause of death by the year 2030 (Mathers and Loncar, 2006). COPD is characterized by airflow limitation that is not fully reversible and a chronic persistent inflammatory process (Pauwels et al., 2001). Tobacco smoking is a significant environmental cause of COPD. However, only approximately $15 \%$ of smokers develop clinically relevant airflow obstruction (Davis and Novotny, 1989). Many individuals, even very heavy smokers, have normal values for forced expiratory volume in one second (FEV1). This phenomenon, as well the familial clustering in patients with COPD (Givelber et al., 1998), indicate that genetic factors might contribute to individual susceptibility to COPD.

During the past few years, genome-wide association studies (GWAS) have become increasingly common in the search for the genetic influences on common chronic diseases, including asthma and COPD (Moffatt et al., 2007; Ober et al., 2008; Pillai et al., 2009). GWAS has revolutionized the identification of susceptibility genes for complex and chronic diseases and has revealed a statistically significant association between COPD and the rs3821104 polymorphism of the X-ray repair cross-complementing protein 5 gene (XRCC5; MIM 194364) in non-Asian populations (Hersh et al., 2010). Given the large differences in the genetic backgrounds of different ethnic populations, replication studies in other populations with more single nucleotide polymorphisms (SNPs) are warranted. The aim of the current study was to investigate whether SNPs in XRCC 5 might be related to the development of COPD in the Chinese Han population. In addition, by stratified analysis and analyses of COPD-related phenotypes, we also intended to better differentiate the actual functional polymorphism of the gene.

\section{MATERIAL AND METHODS}

\section{Study participants}

A total of 680 unrelated COPD patients and 687 normal control subjects from a Southwestern Chinese Han population were included in this case-control association study between 
January 2010 and December 2011. Approval for the study was obtained from the Institutional Review Board of the West China Hospital of Sichuan University and written informed consent was obtained from all subjects. The case group consisted of 680 patients who were diagnosed with COPD at the West China Hospital of Sichuan University according to the following criteria: age $\geq 40$ years, physician-diagnosed COPD, and pulmonary function test showing postbronchodilator FEV1/forced vital capacity (FVC) of less than 70\% (Global Strategy for the Diagnosis, 2011). Patients were excluded from the study if they had an established diagnosis of asthma, lung cancer, a history of atopy, or a known alpha-1 antitrypsin (AAT) deficiency. A total of 687 unrelated healthy subjects, who had no known medical illness or family disorders, acted as control subjects. Efforts were made to match cases and controls by age, gender, and smoking history.

\section{SNP selection and genotyping}

Nine SNPs (rs207906, rs207936, rs3770498, rs6704622, rs12470053, rs3821104, rs3770492, rs4674066, and rs7573191) of the XRCC5 gene were chosen, which were all in the region of chromosome $2 \mathrm{q}$ and were found to be significantly associated with COPD and COPD-related phenotypes in non-Asian populations by recent GWAS and integrative genomic approaches (Hersh et al., 2010). A venous blood sample was drawn from each individual by standard venopuncture. Blood samples were collected in sterile tubes with edetic acid (EDTA) $-\mathrm{Na}_{2}$ anticoagulants and stored at $-20^{\circ} \mathrm{C}$. Genomic DNA was extracted from blood using a commercial extraction kit (Tiangen Biotech Co. Ltd.; Beijing, China) according to manufacturer instructions. Genotyping was carried out commercially by BGI (Shenzhen, China) using Sequenom's iPLEX SNP genotyping protocol developed for measurement with the MassARRAY mass spectrometer (Sequenom; San Diego, CA, USA) (Koren-Michowitz et al., 2008). Genotyping was performed blind to the case or control status of samples. As a quality control measure, approximately $5 \%$ of samples were genotyped in duplicate to check for concordance. In addition, a selection of samples was also genotyped using restriction enzyme digestion or direct sequencing to confirm the genotyping results from BGI.

\section{Statistical analysis}

Age, smoking history, body mass index (BMI), and pulmonary function data are reported as means \pm SD. Hardy-Weinberg equilibrium (HWE) was tested using a goodness-of-fit $\chi^{2}$ test with one degree of freedom. The differences in allele frequencies between cases and controls were tested by using the $\chi^{2}$ test. Logistic regression analyses were performed to test the association between each SNP with COPD case/control status, adjusting for age, gender, BMI, pack-years of smoking, and current smoking status. We also carried out a smoking statusstratified analysis to eliminate the potential impact of cigarettes. Linear regression analyses were performed to assess the relationship between SNPs and quantitative phenotypes (pulmonary function) among COPD cases only and among the entire cohort. The SPSS software version 18.0 was used in statistical evaluations of the above data. The linkage disequilibrium (LD) structure in the XRCC5 region was examined with the program Haploview 4.2 (Broad Institute of MIT and Harvard; Boston, MA, USA) and haplotype analysis was also conducted using the same software (Barrett et al., 2005). A 2-sided value of $\mathrm{P}<0.05$ was considered to be statistically significant. 


\section{RESULTS}

All demographic data and baseline characteristics of the study groups are summarized in Table 1. More males than females participated in this study; however, gender was equally distributed between COPD cases and control subjects. Cases, on average, were older than control subjects (62.74 vs 60.90 years, $\mathrm{P}=0.002)$. Cases had a greater average smoking exposure (pack-years for ever smokers: 33.76 vs 29.17, $\mathrm{P}=0.001$ ). Cases had worse lung function than control subjects, including a lower predicted FEV1 percentage (64.22 vs 102.35\%, respectively) and FEV1/FVC ( 0.54 vs 0.79 , respectively). Locus information and allele frequencies are presented in Table 2. The HWE analysis showed that all genotyped SNPs were in HWE in control subjects.

\begin{tabular}{|c|c|c|c|}
\hline & COPD patients $(\mathrm{N}=680)$ & Controls $(\mathrm{N}=687)$ & $P$ value \\
\hline Male (\%) & $483(71.0)$ & $476(69.3)$ & $0.481^{\text {s }}$ \\
\hline Age $( \pm$ SD $)$ & $62.74( \pm 9.08)$ & $60.90( \pm 10.21)$ & $0.002 *$ \\
\hline $\mathrm{BMI}( \pm \mathrm{SD})$ & $22.45( \pm 3.49)$ & $22.63( \pm 3.32)$ & $0.085^{*}$ \\
\hline \multicolumn{4}{|l|}{ Current smoking status } \\
\hline Non-smoker $(\%)$ & $225(33.1)$ & $231(33.6)$ & \\
\hline Former smoker (\%) & $204(30.0)$ & $165(24.0)$ & $0.028^{\mathrm{s}}$ \\
\hline Current smoker (\%) & $251(36.9)$ & $291(42.4)$ & \\
\hline Pack-years ${ }^{1}$ for ever smokers $( \pm S D)$ & $33.76( \pm 20.70)$ & $29.17( \pm 21.32)$ & $0.001 *$ \\
\hline Post-FEV1 $\%$ predicted $( \pm \mathrm{SD})$ & $64.22( \pm 24.91)$ & $102.35( \pm 15.55)$ & $<0.0001 *$ \\
\hline Post-FEV1/FVC ratio $( \pm$ SD) & $53.58( \pm 12.49)$ & $79.26( \pm 6.14)$ & $<0.0001^{*}$ \\
\hline
\end{tabular}

$\mathrm{COPD}=$ chronic obstructive pulmonary disease; $\mathrm{BMI}=$ body mass index; Post- = post-bronchodilator; FEV1 = forced expiratory volume in 1 second; FVC $=$ forced vital capacity. ${ }^{1}$ Pack-years $=$ (number of cigarettes smoked per day x number of years smoked) / 20. *Student's $t$-test. ${ }^{~}$ Pearson's $\chi^{2}$ test.

Table 2. Characteristics of the XRCC5 SNPs genotyped and allele frequencies of these single nucleotide polymorphism (SNPs) in chronic obstructive pulmonary disease (COPD) patients and controls.

\begin{tabular}{|c|c|c|c|c|c|c|c|}
\hline \multirow[t]{2}{*}{ SNP No. } & \multirow{2}{*}{$\begin{array}{l}\text { Reference } \\
\text { SNP ID }\end{array}$} & \multirow{2}{*}{$\begin{array}{c}\text { Chromosome } \\
\text { position (NCBI) }\end{array}$} & \multirow{2}{*}{$\begin{array}{l}\text { Major/minor } \\
\text { alleles }\end{array}$} & \multirow{2}{*}{$\begin{array}{l}\text { HWE P value } \\
\text { in controls }\end{array}$} & \multicolumn{2}{|c|}{ MAF } & \multirow[t]{2}{*}{ P value* } \\
\hline & & & & & $\operatorname{COPD}(\mathrm{N}=680)$ & Control $(\mathrm{N}=687)$ & \\
\hline 1 & rs3821104 & 216766091 & $\mathrm{~T} / \mathrm{C}$ & 0.754 & 0.042 & 0.064 & $0.010^{\#}$ \\
\hline 2 & rs 12470053 & 216763416 & $\mathrm{G} / \mathrm{A}$ & 0.754 & 0.041 & 0.064 & $0.008^{\#}$ \\
\hline 3 & rs207936 & 216748278 & $\mathrm{C} / \mathrm{T}$ & 0.988 & 0.040 & 0.063 & $0.007^{\#}$ \\
\hline 4 & rs3770498 & 216755705 & $\mathrm{~A} / \mathrm{C}$ & 0.754 & 0.041 & 0.064 & $0.007^{\#}$ \\
\hline 5 & rs6704622 & 216757780 & $\mathrm{~T} / \mathrm{C}$ & 0.754 & 0.041 & 0.064 & $0.007^{\#}$ \\
\hline 6 & rs3770492 & 216766435 & $\mathrm{G} / \mathrm{A}$ & 0.755 & 0.042 & 0.064 & $0.010^{\#}$ \\
\hline 7 & rs4674066 & 216768209 & $\mathrm{~T} / \mathrm{C}$ & 0.754 & 0.042 & 0.064 & $0.010^{\#}$ \\
\hline 8 & rs 7573191 & 216772609 & $\mathrm{~A} / \mathrm{G}$ & 0.754 & 0.041 & 0.064 & $0.007^{\#}$ \\
\hline 9 & rs207906 & 216721146 & $\mathrm{G} / \mathrm{A}$ & 0.611 & 0.095 & 0.095 & 0.965 \\
\hline
\end{tabular}

HWE $=$ Hardy-Weinberg equilibrium; MAF $=$ minor allele frequency. $* \chi^{2}$ test for allele frequency difference between COPD and control. ${ }^{*} \mathrm{P} \leq 0.05$.

The allele frequencies for SNPs in cases and controls are shown in Table 2. Statistically significant associations with COPD were observed in allele distributions $(\mathrm{P}=0.010$ for rs 3821104, $\mathrm{P}=0.008$ for rs12470053, $\mathrm{P}=0.007$ for $\mathrm{rs} 207936, \mathrm{P}=0.007$ for $\mathrm{rs} 3770498, \mathrm{P}=$ 0.007 for rs6704622, $\mathrm{P}=0.010$ for rs3770492, $\mathrm{P}=0.010$ for $\mathrm{rs} 4674066$, and $\mathrm{P}=0.007$ for rs7573191) in the crude analysis. Genotype frequencies by case-control status are given in 
Table 3. The rs207936 SNP differed significantly in the analysis adjusting for age, gender, BMI, pack-years, and current smoking status $(\mathrm{P}=0.038)$. Under the assumption of a dominant mode of inheritance (TT+CT vs CC), the CC genotype was associated with increased risk of COPD for $\mathrm{rs} 207936$ \{odds ratio $[\mathrm{OR}=1.667,95 \%$ confidence interval $(\mathrm{CI}=1.161-2.393)]$ \}

\begin{tabular}{|c|c|c|c|c|c|c|}
\hline \multirow[t]{2}{*}{ Reference SNP ID } & \multirow[t]{2}{*}{ Genotypes } & \multirow[t]{2}{*}{$\operatorname{COPD}(\mathrm{N}=680)$} & \multirow[t]{2}{*}{ Controls $(\mathrm{N}=687)$} & \multicolumn{2}{|c|}{$P$ value } & \multirow[t]{2}{*}{ Adjusted $\mathrm{OR}^{\$}(95 \% \mathrm{Cl}$} \\
\hline & & & & Unadjusted & Adjusted* & \\
\hline \multirow[t]{3}{*}{ rs3821104 } & TT & $623(91.6)$ & $603(87.8)$ & 0.126 & 0.069 & 1 \\
\hline & $\mathrm{TC}$ & $57(8.4)$ & 80 (11.6) & & & $1.534(1.068-2.206)$ \\
\hline & $\mathrm{CC}$ & 0 & $4(0.6)$ & & & $1.755 \mathrm{E} 9(0.000-)$ \\
\hline \multirow{3}{*}{ rs 12470053} & GG & $623(91.8)$ & $603(87.8)$ & 0.105 & 0.055 & 1 \\
\hline & GA & $56(8.2)$ & 80 (11.6) & & & $1.566(1.087-2.254)$ \\
\hline & AA & 0 & $4(0.6)$ & & & $1.759 \mathrm{E} 9(0.000-)$ \\
\hline \multirow[t]{3}{*}{ rs207936 } & $\mathrm{CC}$ & $625(91.9)$ & $603(87.8)$ & 0.059 & $0.038^{\#}$ & 1 \\
\hline & CT & $55(8.1)$ & $81(11.8)$ & & & $1.609(1.118-2.316)$ \\
\hline & TT & 0 & $3(0.4)$ & & & $1.588 \mathrm{E} 9(0.000-)$ \\
\hline \multirow[t]{3}{*}{ rs3770498 } & AA & $624(91.8)$ & $603(87.8)$ & 0.103 & 0.059 & 1 \\
\hline & $\mathrm{AC}$ & $56(8.2)$ & 80 (11.6) & & & $1.555(1.080-2.238)$ \\
\hline & $\mathrm{CC}$ & 0 & $4(0.6)$ & & & $1.756 \mathrm{E} 9(0.000-)$ \\
\hline \multirow[t]{3}{*}{ rs 6704622} & TT & $624(91.8)$ & $603(87.8)$ & 0.103 & 0.059 & 1 \\
\hline & $\mathrm{TC}$ & $56(8.2)$ & 80 (11.6) & & & $1.555(1.080-2.238)$ \\
\hline & $\mathrm{CC}$ & 0 & $4(0.6)$ & & & $1.756 \mathrm{E} 9(0.000-)$ \\
\hline \multirow[t]{3}{*}{ rs3770492 } & GG & $623(91.6)$ & $602(87.8)$ & 0.124 & 0.068 & 1 \\
\hline & GA & $57(8.4)$ & $80(11.7)$ & & & $1.536(1.069-2.208)$ \\
\hline & $\mathrm{AA}$ & 0 & $4(0.5)$ & & & $1.760 \mathrm{E} 9(0.000-)$ \\
\hline \multirow[t]{3}{*}{ rs4674066 } & TT & 623 (91.6) & $603(87.8)$ & 0.126 & 0.069 & 1 \\
\hline & $\mathrm{TC}$ & $57(8.4)$ & 80 (11.6) & & & $1.534(1.068-2.206)$ \\
\hline & $\mathrm{CC}$ & 0 & $4(0.6)$ & & & $1.755 \mathrm{E} 9(0.000-)$ \\
\hline \multirow{3}{*}{ rs7573191 } & AA & $624(91.8)$ & $603(87.8)$ & 0.103 & 0.059 & \\
\hline & $\mathrm{AG}$ & $56(8.2)$ & 80 (11.6) & & & $1.555(1.080-2.238)$ \\
\hline & GG & 0 & $4(0.6)$ & & & $1.756 \mathrm{E} 9(0.000-)$ \\
\hline \multirow[t]{3}{*}{ rs207906 } & GG & $556(81.8)$ & $560(81.5)$ & 0.925 & 0.919 & 1 \\
\hline & GA & $119(17.5)$ & $123(17.9)$ & & & $1.019(0.769-1.350)$ \\
\hline & $\mathrm{AA}$ & $5(0.7)$ & $4(0.6)$ & & & $0.770(0.201-2.939)$ \\
\hline
\end{tabular}

*Adjusted by logistic regression for age, gender, BMI, pack-years, and current smoking status. ${ }^{\$}$ Odds ratios are relative to the major homozygous genotype. ${ }^{*} \mathrm{P} \leq 0.05$.

We next carried out a smoking status stratification analysis to eliminate the potential confounding effect caused by differences in smoking history. Results showed that none of the SNPs was significantly associated with COPD in non-smokers $(\mathrm{N}=456)$ and former smokers $(\mathrm{N}=369)$. When the analysis was conducted in current smokers $(\mathrm{N}=542)$, the SNP rs207936 was associated with COPD $(\mathrm{P}=0.046$, Table 4$)$. Under the assumption of a dominant mode of inheritance (TT $+\mathrm{CT} v s \mathrm{CC}$ ), the CC genotype was associated with increased risk of COPD for rs207936 $(\mathrm{OR}=2.392,95 \% \mathrm{CI}=1.283-4.458)$.

Haplotype analysis, which tests associations using several polymorphisms, can sometimes demonstrate genetic influences that would not otherwise be detected by the analysis of single polymorphisms. The values for LD between the nine SNPs are shown in Figure 1. This analysis revealed very strong levels of LD between the SNPs in the XRCC5 gene except for rs207906 $\left(\mathrm{R}^{2} \geq 0.9\right)$. We constructed the haplotypes of cases and controls. Eight SNPs (rs207936, rs3770498, rs6704622, rs12470053, rs3821104, rs3770492, rs4674066, and rs7573191) were classified in two major haplotypes (CATGTGTA and TCCACACG), and significant differences between case and control groups were observed $(\mathrm{P}=0.0054$ and $\mathrm{P}=$ 0.0081 , respectively, Table 5). 
Table 4. Genetic association results between single nucleotide polymorphisms (SNPs) in XRCC5 and chronic obstructive pulmonary disease (COPD) by smoking status-stratified analysis.

\begin{tabular}{|c|c|c|c|c|}
\hline \multirow[t]{2}{*}{$\overline{\text { SNP No. }}$} & \multirow[t]{2}{*}{ Reference SNP ID } & \multicolumn{3}{|c|}{$\mathrm{P}$ values by different smoking status } \\
\hline & & Non-smokers* $(\mathrm{N}=456)$ & Former smokers ${ }^{\S}(\mathrm{N}=369)$ & Current smokers $\$^{\$}(\mathrm{~N}=542)$ \\
\hline 1 & rs3821104 & 0.121 & 0.424 & 0.130 \\
\hline 2 & rs12470053 & 0.093 & 0.424 & 0.130 \\
\hline 3 & rs207936 & 0.203 & 0.248 & $0.046^{\#}$ \\
\hline 4 & rs3770498 & 0.121 & 0.396 & 0.130 \\
\hline 5 & rs6704622 & 0.121 & 0.396 & 0.130 \\
\hline 6 & rs3770492 & 0.121 & 0.424 & 0.127 \\
\hline 7 & rs4674066 & 0.121 & 0.424 & 0.130 \\
\hline 8 & rs7573191 & 0.121 & 0.396 & 0.130 \\
\hline 9 & rs 207906 & 0.479 & 0.772 & 0.121 \\
\hline
\end{tabular}

*P values adjusted by logistic regression for age, gender, BMI in non-smokers. ${ }^{\$} \mathrm{P}$ values adjusted by logistic regression for age, gender, BMI, and pack-years in former smokers and current smokers. ${ }^{\#} \mathrm{P} \leq 0.05$.

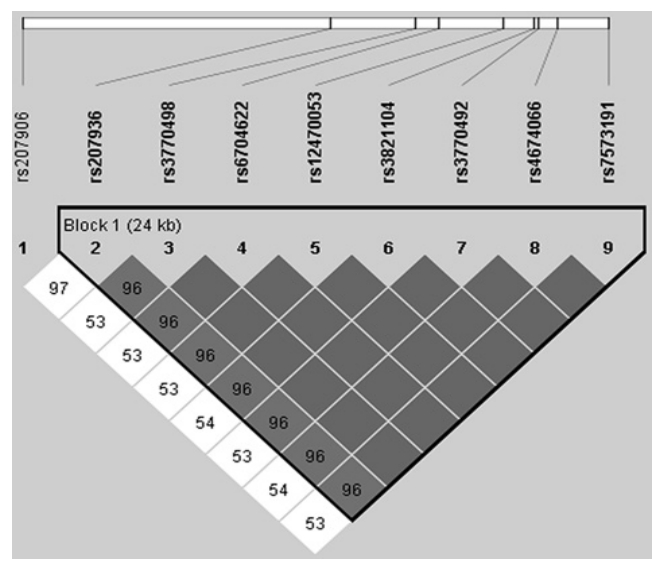

Figure 1. Linkage disequilibrium (LD) among single nucleotide polymorphisms analyzed in chromosome 2q. LD values are presented as $\mathrm{r}^{2}$ and LD block was defined according to the confidence intervals in the Haploview software.

Table 5. Association of $X R C C 5$ haplotypes with chronic obstructive pulmonary disease.

\begin{tabular}{lccc}
\hline Haplotype & Frequencies & Case, control ratios & P value of $\chi^{2}$ test \\
\hline CATGTGTA & 0.945 & $1300: 58,1282: 92$ & 0.0054 \\
TCCACACG & 0.050 & $53: 1305,84: 1290$ & 0.0081 \\
\hline
\end{tabular}

Significant linkage to a region on chromosome $2 \mathrm{q}$ for COPD-related traits was found in the Boston Early-Onset COPD Families study by a genome-wide linkage analysis, and SERPINE2 was identified as a potential COPD susceptibility gene on chromosome 2q; however, there are likely to be additional COPD genes in this region (Silverman et al., 2002; Malhotra et al., 2003; Postma et al., 2005; DeMeo et al., 2004, 2006). To determine whether the $X R C C 5$ region was associated with COPD-related traits, quantitative genetic association analysis was carried out for the predicted FEV1 percentage and FEV1/FVC using general linear models under the assumption of an additive mode of inheritance, adjusting for age, gender, BMI, pack-years, and current smoking status. However, no significant differences were observed (Table 6). 


\begin{tabular}{|c|c|c|c|c|}
\hline \multirow[t]{2}{*}{ Reference SNP ID } & \multicolumn{4}{|c|}{$\mathrm{P}$ values for pulmonary function phenotypes } \\
\hline & $\begin{array}{l}\text { FEV } 1 \% \text { predicted } \\
\text { (case only) }\end{array}$ & $\begin{array}{l}\text { FEV1/FVC } \\
\text { (case only) }\end{array}$ & $\begin{array}{l}\text { FEV1\% predicted } \\
\text { (all subjects) }\end{array}$ & $\begin{array}{l}\text { FEV1/FVC } \\
\text { (all subjects) }\end{array}$ \\
\hline rs3821104 & 0.454 & 0.816 & 0.693 & 0.614 \\
\hline rs12470053 & 0.507 & 0.920 & 0.743 & 0.688 \\
\hline rs207936 & 0.256 & 0.442 & 0.431 & 0.331 \\
\hline rs 3770498 & 0.345 & 0.696 & 0.597 & 0.536 \\
\hline rs6704622 & 0.345 & 0.696 & 0.597 & 0.536 \\
\hline rs3770492 & 0.454 & 0.816 & 0.696 & 0.618 \\
\hline rs4674066 & 0.454 & 0.816 & 0.693 & 0.614 \\
\hline rs7573191 & 0.345 & 0.696 & 0.597 & 0.536 \\
\hline rs207906 & 0.954 & 0.762 & 0.806 & 0.983 \\
\hline
\end{tabular}

Analyses of pulmonary function phenotypes were adjusted for age, gender, BMI, current smoking status, and packyears by linear regression. Analyses including all subjects were additionally adjusted for COPD case/control status.

\section{DISCUSSION}

COPD is a complex disease caused by multiple genetic and environmental factors; therefore, it is essential to obtain more data from different populations to confirm the role of the XRCC5 gene in COPD. GWAS conducted in four independent patient samples revealed a statistically significant association between COPD and XRCC5 polymorphisms in non-Asian populations. However, this association was not significant in any of the cohorts individually (Hersh et al., 2010). When such conflicting results among different studies occur, genetic heterogeneity may be an important factor (Hersh et al., 2005). In some instances, even if the same genetic variant was identified in the association in each population, the LD relationships of this variant with neighboring genetic polymorphisms varied between ethnic groups. A replication case-control study in the Chinese Han population (275 cases and 434 controls) found an association between XRCC5 and COPD. The limitation of this study was that only one SNP was investigated and the COPD-related phenotypes were not evaluated. Therefore, information about other SNPs in XRCC5 in this Chinese population and about their association with COPD-related phenotypes was not available (Guo et al., 2011). The effect of a single polymorphism may be subtle, whereas the combination of several polymorphisms may be more predictive of an individual's response to an exposure. In the present study, we provided new genotyping data of XRCC5 SNPs in the Han Chinese population by collecting data of a large cohort of COPD cases and controls (680 cases and 687 controls). Nine SNPs, including rs207906, rs207936, rs3770498, rs6704622, rs12470053, rs3821104, rs3770492, rs4674066, and rs7573191, with minor allele frequencies greater than 5\% were chosen. Ultimately, a significant association was found between rs207936 at the XRCC5 locus and COPD patients, especially in current smokers, indicating that this polymorphism of the XRCC5 gene might contribute to the development of COPD in the Chinese Han population, and this association might be mediated by smoking behavior.

The XRCC5 gene, mapped to chromosome $2 \mathrm{q} 35$, contains 21 exons spanning approximately $97 \mathrm{~kb}$. It encodes a deduced 732 amino acid protein, an $80-\mathrm{kDa}$ subunit of the $\mathrm{Ku}$ autoantigen, which is a heterodimer protein that is also known as ATP-dependent DNA helicase II or DNA repair protein, and is involved in DNA double-strand break repair and immunoglobulin V (D) J rearrangement (Nussenzweig et al., 1996). XRCC5 is also known as 
$K u 80$ or $K u 86$. There are several potential mechanisms for the role of XRCC5 in the development of COPD. For example, Ku86-/- mice developed pulmonary emphysema, early aging, and an autoimmune component, implicating Ku80/86 in the development of COPD (Agusti et al., 2003; Taraseviciene-Stewart et al., 2006; Lee et al., 2007; Cosio et al., 2009).

A small sample size can introduce some bias into association studies (Hersh et al., 2005). To investigate whether our sample size was sufficient to detect genetic determinants of minor effect, we assessed the power of our sample size by using the Quanto software (developed by Jim Gauderman and John Morrison of the Department of Preventive Medicine of the University of Southern California). With the $8.8 \%$ disease prevalence in the Chinese population (Zhou et al., 2009), for a variant with a 0.04 minor allele frequency (minimum frequency of 9 SNPs) in an additive model, our sample size provided $60.7 \%$ power to detect a genetic relative risk (OR) of 1.5 , whereas for a genotypic OR of 2.0 , the power increased to $\geq 90 \%$ at a significance level of 0.05 with a 2 -sided alternative hypothesis.

To our knowledge, this is the first study to investigate the association of the SNPs rs3821104, rs12470053, rs207936, rs3770498, rs6704622, rs3770492, rs4674066, rs7573191, and rs207906 of the XRCC5 gene with COPD and COPD-related phenotypes in a large cohort of Chinese Han patients. In summary, we performed a comprehensive investigation of XRCC5 gene polymorphisms. The SNP showing significant differences may be useful for predicting COPD susceptibility or possible preventive intervention. Given that the clear functions of the SNPs evaluated in the current study have not yet been reported and that the full sequence of the $X R C C 5$ gene was not investigated, more functional studies in large, homogeneous populations with COPD will be required to determine the potential impact of XRCC5 variants on COPD.

\section{ACKNOWLEDGMENTS}

Research supported by grants \#31071009 and \#8107003 from the National Natural Science Foundation of China, grant \#2010-439 from the Ministry of Health of China, and grants \#2010SZ0287 and \#2012SZ0131 from the Sichuan Science and Technology Agency.

\section{REFERENCES}

Agusti A, MacNee W, Donaldson K and Cosio M (2003). Hypothesis: does COPD have an autoimmune component? Thorax 58: 832-834.

Barrett JC, Fry B, Maller J and Daly MJ (2005). Haploview: analysis and visualization of LD and haplotype maps. Bioinformatics 21: 263-265.

Cosio MG, Saetta M and Agusti A (2009). Immunologic aspects of chronic obstructive pulmonary disease. N. Engl. J. Med. 360: 2445-2454.

Davis RM and Novotny TE (1989). The epidemiology of cigarette smoking and its impact on chronic obstructive pulmonary disease. Am. Rev. Respir. Dis. 140: S82-S84.

DeMeo DL, Celedon JC, Lange C, Reilly JJ, et al. (2004). Genome-wide linkage of forced mid-expiratory flow in chronic obstructive pulmonary disease. Am. J. Respir. Crit. Care Med. 170: 1294-1301.

DeMeo DL, Mariani TJ, Lange C, Srisuma S, et al. (2006). The SERPINE2 gene is associated with chronic obstructive pulmonary disease. Am. J. Hum. Genet. 78: 253-264.

Givelber RJ, Couropmitree NN, Gottlieb DJ, Evans JC, et al. (1998). Segregation analysis of pulmonary function among families in the Framingham Study. Am. J. Respir. Crit. Care Med. 157: 1445-1451.

Global Strategy for the Diagnosis (2011). Management and Prevention of chronic obstructive pulmonary disease, Global Initiative for Chronic Obstructive Lung Disease (GOLD) (Updated 2011).

Guo Y, Lin H, Gao K, Xu H, et al. (2011). Genetic analysis of IREB2, FAM13A and XRCC5 variants in Chinese Han 
patients with chronic obstructive pulmonary disease. Biochem. Biophys. Res. Commun. 415: 284-287.

Hersh CP, Demeo DL, Lange C, Litonjua AA, et al. (2005). Attempted replication of reported chronic obstructive pulmonary disease candidate gene associations. Am. J. Respir. Cell Mol. Biol. 33: 71-78.

Hersh CP, Pillai SG, Zhu G, Lomas DA, et al. (2010). Multistudy fine mapping of chromosome 2q identifies XRCC5 as a chronic obstructive pulmonary disease susceptibility gene. Am. J. Respir. Crit. Care Med. 182: 605-613.

Koren-Michowitz M, Shimoni A, Vivante A, Trakhtenbrot L, et al. (2008). A new MALDI-TOF-based assay for monitoring JAK2 V617F mutation level in patients undergoing allogeneic stem cell transplantation (allo SCT) for classic myeloproliferative disorders (MPD). Leuk. Res. 32: 421-427.

Lee SH, Goswami S, Grudo A, Song LZ, et al. (2007). Antielastin autoimmunity in tobacco smoking-induced emphysema. Nat. Med. 13: 567-569.

Malhotra A, Peiffer AP, Ryujin DT, Elsner T, et al. (2003). Further evidence for the role of genes on chromosome 2 and chromosome 5 in the inheritance of pulmonary function. Am. J. Respir. Crit. Care Med. 168: 556-561.

Mathers CD and Loncar D (2006). Projections of global mortality and burden of disease from 2002 to 2030. PLoS Med. 3: e442.

Moffatt MF, Kabesch M, Liang L, Dixon AL, et al. (2007). Genetic variants regulating ORMDL3 expression contribute to the risk of childhood asthma. Nature 448: 470-473.

Nussenzweig A, Chen C, da Costa Soares V, Sanchez M, et al. (1996). Requirement for Ku80 in growth and immunoglobulin V(D)J recombination. Nature 382: 551-555.

Ober C, Tan Z, Sun Y, Possick JD, et al. (2008). Effect of variation in CHI3L1 on serum YKL-40 level, risk of asthma, and lung function. N. Engl. J. Med. 358: 1682-1691.

Pauwels RA, Buist AS, Calverley PM, Jenkins CR, et al. (2001). Global strategy for the diagnosis, management, and prevention of chronic obstructive pulmonary disease. NHLBI/WHO Global Initiative for Chronic Obstructive Lung Disease (GOLD) Workshop summary. Am. J. Respir. Crit. Care Med. 163: 1256-1276.

Pillai SG, Ge D, Zhu G, Kong X, et al. (2009). A genome-wide association study in chronic obstructive pulmonary disease (COPD): identification of two major susceptibility loci. PLoS Genet. 5: e1000421.

Postma DS, Meyers DA, Jongepier H, Howard TD, et al. (2005). Genomewide screen for pulmonary function in 200 families ascertained for asthma. Am. J. Respir. Crit. Care Med. 172: 446-452.

Silverman EK, Palmer LJ, Mosley JD, Barth M, et al. (2002). Genomewide linkage analysis of quantitative spirometric phenotypes in severe early-onset chronic obstructive pulmonary disease. Am. J. Hum. Genet. 70: 1229-1239.

Taraseviciene-Stewart L, Burns N, Kraskauskas D, Nicolls MR, et al. (2006). Mechanisms of autoimmune emphysema. Proc. Am. Thorac. Soc. 3: 486-487.

Zhou YM, Wang C, Yao WZ, Chen P, et al. (2009). Current status of prevention and management of chronic obstructive pulmonary disease in rural area in China. Zhonghua Nei Ke. Za Zhi 48: 358-361. 